\title{
O Uso de Vídeos Didáticos como Ferramenta Pedagógica nas Escolas Atendidas pelo PIBID - Química da UFCG - CFP.
}

Manoel Vanderson V. Batista*; (Graduando em Licenciatura em Química CFP/UFCG, Cajazeiras - PB) J osé Estrela dos Santos; (Professor Doutor, UACEN/CFP/UFCG, Cajazeiras - PB) J osé de Ribamar Bringel Filho; (Professor da E. E. E. F. M. Professor Manoel Mangueira Lima, Cajazeiras - PB)

Camila Marcelino de Oliveira; (Graduanda em Licenciatura em Química CFP/UFCG, Cajazeiras - PB) Mikaely Soares de Abrantes; (Graduanda em Licenciatura em Química CFP/UFCG, Cajazeiras - PB)

*Email: manoelvandersonprojetos@gmail.com

\section{Resumo:}

Em tempos de desenvolvimento tecnológico, a presente pesquisa realizada com alunos da Escola Estadual de Ensino Fundamental e Médio Professor Manoel Mangueira Lima e da Escola Estadual de Ensino Fundamental e Médio Cristiano Cartaxo, ambas localizada na cidade de Cajazeiras - PB, e atendidas pelo subprojeto de Química do Programa Institucional de Iniciação à Docência (PIBID) do CFP/UFCG, apresenta dados sobre o uso de vídeos em atividades de ensino e aprendizagem. Teve como objetivo analisar a utilização dos vídeos didáticos, como ferramenta pedagógica nas aulas de Química, nas referidas escolas, e refletir sobre o papel deste recurso educativo como instrumento de aprendizagem. Em função da metodologia, realizou-se a exibição de um vídeo didático sobre reações químicas e, a seguir, houve aplicação de questionários aos estudantes, contendo perguntas abertas e fechadas, que objetivou colher informações acerca das concepções dos estudantes, referente ao vídeo didático como ferramenta pedagógica. Os dados evidenciados nos gráficos reforçam o entendimento dos participantes da pesquisa. A atividade foi empreendida por bolsista do subprojeto Química do PIBID do CFP/UFCG, que atuam nas duas escolas, no 1o ano do Ensino Médio de cada escola aqui elencada. A proposta se mostrou positiva, à medida que forneceu oportunidade a professores e alunos para refletirem sobre a importância dos vídeos didáticos para complementar e acrescer conhecimentos antes discutidos apenas na sala de aula.

Pallavras-chave:

Vídeos Didáticos; Ensino de Química; PIBID; Ferramenta Pedagógica; Ensino e aprendizagem. 


\section{Introdução}

Com o advento das tecnologias da informação e da comunicação (TICs) houve uma significativa mudança na educação, notadamente na visualização do conhecimento. Nesse cenário, os vídeos assumiram um papel relevante para aproximar o conhecimento verbalizado e a linguagem que o vídeo pode proporcionar. As imagens têm um forte apelo emocional e afetivo, mostrando-se, por vezes, mais eficientes que somente as palavras na hora de provocar emoções. Logo, podem mexer e se relacionar com os sentidos, penetrando em outras realidades, como as de dimensões microscópicas, no caso da química, auxiliando os estudantes na construção de modelos mentais acerca dos fenômenos e propiciando a superação de barreiras existentes em alguns conceitos abstratos e complexos (ARROIO; GIORDAN, 2006).

A utilização de vídeos didáticos em sala de aula é reconhecida como um recurso de extrema utilidade para promover melhoria no processo ensino-aprendizagem de Química.

[...] Vídeos e filmes possibilitam a observação de fenômenos que demandam um tempo mais longo para ocorrer, principalmente aqueles relacionados a alterações no meio ambiente. Também favorecem a visualização de processos que ocorrem em realidades distintas da comunidade em que a escola está inserida, por exemplo, a obtenção industrial de metais, plásticos, tecidos, etc.

A exibição de vídeos e filmes não pode ser encarada como uma atividade de lazer ou em substituição a uma aula teórica para suprir a ausência de professor (SILVA; MACHADO; TUNES apud SANTOS; MALDANER, 2010, p.254).

A prática do uso do vídeo como recurso pedagógico traz a possibilidade de utilizar não somente palavras, mas também imagens e sons. Nesse aspecto, vale ressaltar que os vídeos se utilizam de efeitos visuais (gráficos, animações, legendas, etc.) para reforçar uma mensagem veiculada por esse recurso audiovisual. Sua linguagem possibilita o professor deixar de ser um informador passando a ser um mediador que fomenta a autonomia do aluno, e demonstrar que as imagens do vídeo mostram-se mais eficazes do que a palavra na hora de provocar emoções. Sendo assim, fica claro que o vídeo desempenha um papel importante com sua capacidade de provocar emoções e sensações.

Mesmo com a diversidade de vídeos que atualmente são disponibilizados em sites específicos, a exemplo do Youtube, ainda é incipiente o uso destes como recurso didático. Os professores que utilizam esse recurso o fazem de modo limitado, gerando implicações negativas no processo de ensino e aprendizagem. Isto pode desvalorizar o potencial de uso dos vídeos, acarretando certo descrédito em relação ao trabalho docente quando este é mal realizado (LIMA, 2001 apud VASCONCELOS et al, 2013).

A presente pesquisa foi empreendida pelos bolsistas do subprojeto de Química do Programa Institucional de Iniciação à Docência (PIBID) do CFP/UFCG, atuantes na Escola Estadual de Ensino Fundamental e Médio Professor Manoel Mangueira Lima e na Escola Estadual de Ensino Fundamental e Médio Cristiano Cartaxo, ambas localizada na cidade de Cajazeiras - PB, tendo como objetivo analisar a utilização dos vídeos didáticos, como ferramenta pedagógica nas aulas de Química, nas referidas escolas, e refletir sobre o papel deste recurso educativo como instrumento de aprendizagem.

\section{Metodologia}

Este estudo foi realizado com 40 alunos do $1^{\circ}$ ano do ensino médio de duas escolas públicas de Cajazeiras - PB que são atendidas pelo subprojeto PIBID - Química do CFP/UFCG Campus de Cajazeiras. A pesquisa foi também assistida pelos professores responsáveis por esta turma, e teve o seguinte desenvolvimento:

i) Apresentação do conteúdo "reações químicas” pelo professor da disciplina; 
ii) Exibição de um vídeo: "O metal que faz a água explodir (Superquímica)”, que se encontra no site: http://www.manualdomundo.com.br/2013/02/experiencia-incrivel-de-quimicasodio-com-agua;

iii) Aplicação de um questionário acerca do assunto "reações químicas" com perguntas semiestruturadas referente à exibição do vídeo. Os questionários eram compostos por 10 (dez) questões, entre as quais, 8 (oito) fechadas e 2 (duas) abertas. De posse das respostas dadas pelos docentes foi feita uma categorização e análise das mesmas.

\section{Resultados e Discussão}

A maneira como os alunos responderam a esta pesquisa mostra que os mesmos possuem diferentes graus de linguagem científica. A partir dos dados obtidos, com as amostras selecionadas, foi possível analisar que a utilização de vídeos didáticos nas aulas de química das referidas escolas é satisfatória, como mostra o gráfico abaixo.

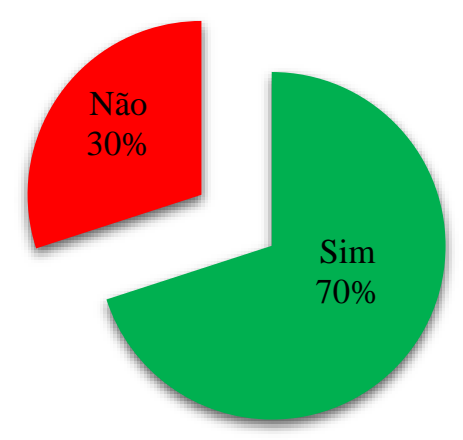

Gráfico 1. Os vídeos didáticos são utilizados em sala de aula?

Relativo à utilização de vídeos didáticos nas aulas de química, a maioria dos alunos consultados, acham necessária a sua utilização, bem como deve ser mais usada como ferramenta didática para facilitar a aprendizagem, motivar e despertar o interesse dos envolvidos nesse processo de ensino. A incorporação do uso do vídeo à prática pedagógica não é tarefa fácil, pois antes é necessária a observação de várias questões para que o vídeo se torne um recurso didático efetivo para o ensino/aprendizagem e não apenas um mero transmissor de informações.



Gráfico 2. Você acha que o vídeo utilizado facilitou o aprendizado?

Percebe-se, vendo o gráfico acima, que o vídeo exibido para os alunos, da amostra selecionada, teve um respaldo positivo, facilitando a aprendizagem do conteúdo "reações químicas", 
dado com antecedência pelos professores de química da referida série selecionada. O uso didático do vídeo serve como um reforço ao conteúdo e, ao mesmo tempo, motiva e desperta o interesse dos alunos, por ser diferente da rotina de sala.

Com base no que foi assistido no vídeo sobre reações químicas, foi solicitado aos alunos uma interpretação ou uma definição do que venha a ser uma reação química, ficando facultado aos mesmos respostas mais compreensível para seu entendimento. Assim como mostra o Gráfico 3, percebeu-se uma significativa melhora no entendimento dos alunos, embora possa melhorar a aprendizagem com atividades complementares, como por exemplo jogos lúdicos.

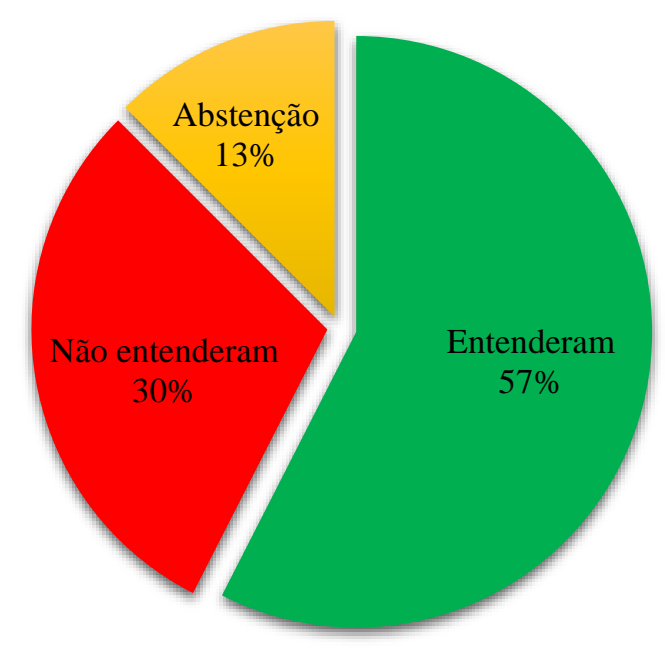

Gráfico 3. Com base no que foi visto, defina reação química.

Talvez pudéssemos questionar sobre por que um percentual ainda grande de alunos não tenha compreendido o tema. Mas, neste trabalho não analisamos a qualidade do vídeo nem a conexão dele com outros conteúdos. È importante frisar que o uso inadequado do recurso audiovisual e sem uma discussão prévia do conteúdo pode inviabilizar todo processo de aprendizagem, o que não é o caso específico da amostra investigada.

É importante considerar, ainda, qual a linguagem que está sendo adotada no vídeo, e se o nível em que as ideias são enunciadas se adapta àquele grupo de alunos ou aquela comunidade escolar. Importa frisar, também, que algumas considerações devem ser formadas antes da utilização do audiovisual para os alunos. No mesmo sentido, é preciso considerar que em um país com as dimensões continentais como o nosso e com vários aspectos culturais e sociais, nem sempre é possível produzir uma vídeo-aula em determinada região do País que dialogue, ao mesmo tempo, com outras comunidades que têm problemas localizados, não sendo possível uma contextualização do problema.

\section{Conclusões}

As referidas escolas de atuação do subprojeto possuem equipamentos suficientes para realização dessa atividade propostas pela equipe do PIBID - Química do CFP/UFCG, como TV, DVD player, projetor multimídia, caixas de som, laboratório de informática, e internet. São equipamentos e meios que potencializam a aplicação de vídeos didáticos como ferramenta pedagógica, com o intuito de reforçar os conteúdos dados pelo professor (a) em sala de aula, com sua mediação.

Após esse trabalho de diagnóstico, constatamos que a maioria dos professores praticamente não utiliza esse recurso didático em sala de aula, muitas vezes por não estarem preparados para avaliar o vídeo e a forma de inserir no ensino. Constatamos também que o vídeo didático é uma ferramenta pedagógica poderosa e pontual, pois reforça aqueles conteúdos dados pelo professor em sala de aula, com sua mediação pedagógica. Portanto, através da análise das perguntas feitas aos alunos, pode-se perceber que a prática metodológica do vídeo didático desenvolveu uma aprendizagem mais eficaz e 
dinâmica referente ao conteúdo "reações químicas" despertando o interesse do aluno e paralelamente facilitando as tarefas didáticas do professor em sala de aula.

\section{USING EDUCATIONAL VIDEOS AS A PEDAGOGICAL TOOL AT SCHOOLS ASSISTED BY PIBID-CHEMISTRY PROJECT OF UFCG-CFP}

Albstract:In times of technological development, this research presents data on the use of video in teaching and learning activities; it was performed with students from Professor Manoel Mangueira Lima Primary and Secondary State School as well as students from Cristiano Cartaxo Primary and Secondary State School, both located in Cajazeiras - PB, and both assisted by the Chemistry subproject of the Institutional Program of Introduction to Teaching (PIBID) of CFP/UFCG. We aimed to analyze the use of educational videos, as a pedagogical tool in Chemistry classes, at the mentioned schools; we also aimed to reflect on the role of this educational resource as a learning tool. Following the methodology, it held the exhibition of an educational video about chemical reactions, and then there was an application of questionnaires for the students, containing objective and subjective questions aimed to gather information about the conceptions of the students, referring to the didactic video as a pedagogical tool. The data highlighted in the graphs enhance the understanding of participants of the research. The activity was done by scholarship students of a Chemistry PIBID subproject of CFP / UFCG; they are acting at both schools in the $1^{\text {st }}$ year of high school of each educational institution that was cited before. The proposal was positive, as it provided an opportunity for teachers and students to reflect on the importance of educational videos to complement and add the knowledge that was usually discussed only in the classroom.

Keywords: Educational Videos; Chemistry Education; PIBID; Educational Tool; Teaching and Learning.

\section{Referências bibliográficas}

ARROIO, A.; GIORDAN, M. O vídeo educativo: Aspectos da organização do ensino. Química Nova na Escola, $n^{\circ} 24$, p. 8-11, Novembro de 2006.

SILVA, José Luiz da; SILVA, Débora Antonio da; MARTINI, Cleber; DOMIGOS, Diane Cristina Araújo; LEAL, Priscilla Gonçalves; BENEDETTI FILHO, Edemar; FIORUCCI, Antonio Rogério. A Utilização de Vídeos Didáticos nas Aulas de Química do Ensino Médio para Abordagem Histórica e Contextualizada do Tema Vidros. Química Nova na Escola, Vol. 34, n 4, p. 189-200, Novembro de 2012.

SILVA, H.R. R; SILVA, J.T; SOUSA, M. S. A utilização de vídeos didáticos como uma medida inovadora para o ensino de Química. In: Anais do SIMPEQUI, Simpósio brasileiro de educação química. Fortaleza - CE: Agosto de 2014.

SILVA, Roberto Ribeiro da; MACHADO, Patrícia Lootens; TUNES, Elizabeth. Experimentar Sem Medo de Errar. p. 231-261. In: SANTOS, Wilson Luiz Pereira dos; MALDANER, Otavio Aloisio. (org.) Ensino de Química em foco. 4aㅡ Ed. Ijuí: UNIJUI, 2010.

VASCONCELOS, Flávia C. G. C. de; MELO, Simone K. S. de; ARROIO, Agnaldo; LEÃO, Marcelo B. C. O uso vídeos no ensino de química: análise da temática nas publicações da química nova na escola. In: Anais do IX CONGRESSO INTERNACI ONAL SOBRE INVESTIGACIÓN EN DIDÁCTICA DE LAS CIENCIAS, COMUNICACIÓN: Girona - ES, 2013, p. 3624-3630. 
O metal que faz a água explodir (Superquímica). Disponível em http://www.manualdomundo.com. br/2013/02/experiencia-incrivel-de-quimica-sodio-com-agua/. Acesso às 17:22 h do dia 20 de Junho de 2015. 